\title{
RESPONSIVENESS OF PAIN AND SYMPTOM'S ITEMS OF KNEE INJURY AND OSTEOARTHRITIS OUTCOME SCORE (KOOS) TO THE AQUATIC EXERCISE
}

\author{
Flávia Yázigi ${ }^{1}$, Diogo Veiga ${ }^{2}$, Pablo J. Marcos-Pardo ${ }^{3}$, Margarida Espanha ${ }^{1}$ \\ ${ }^{1}$ Department of Sport and Health, Universidade de Lisboa, Faculdade de Motricidade Humana, CIPER, , P-1499-002 Lisbon, Portugal \\ 2 Department of Sport and Health, Universidade de Lisboa, Faculdade de Motricidade Humana, Portugal. \\ ${ }^{3}$ Catholic University of Murcia (UCAM), Faculty of Sport, Campus de los Jerónimos, 30107, Murcia, España.
}

OPEN ACCES

Correspondencia:

Flávia Yázigi

Department of Sport and Health Universidade de Lisboa, Faculdade de Motricidade Humana, CIPER, $\mathrm{P}$ fyazigi@fmh.u

Funciones de los autores: Todos los autores trabajaro equitativamente en la consecución del trabajo

Recibido: 5/06/2018 Aceptado: 16/11/2018 Publicado: 31/01/2019

Citación

Yázigi, F., Veiga, D., Marcos-Pardo, P. J., \& Espanha (2019). Responsiveness of pain and symptom's items of Knee Injury and osteoarthritis outcome score (KOOS) to the aquatic exercise. RIAA. Revista de Investigación en Actividades Acuáticas,

Creative Commons License sta obra está bajo una licencia de Creative Commons ReconocimientoNoComercial-Compartir-Igua 4.0 Internacion
Background: Pain is the main symptom of Knee Osteoarthritis (KOA) and aquatic exercise has been indicated as an effective nonpharmacological treatment for KOA symptoms. In general, KOA pain is assessed by simple scales or by multicomponent self-reported questionnaires, mainly the Knee Injury and Osteoarthritis Outcome Score (KOOS) and WOMAC Osteoarthritis Index. Some studies had reported the effectiveness of aquatic exercise on KOOS pain dimension but not on each pain item.

Objectives: This study aimed to investigate how pain items of KOOS questionnaire are affected by 3 months' aquatic exercise program for overweight and obese individuals with KOA (PICO).

Method: Eligibility criteria were $40 \leq$ age $\leq 65$ years; $\mathrm{BMI} \geq 28 \mathrm{~kg} / \mathrm{m}^{2}$; clinical and radiographic KOA. Participants were randomized in aquatic exercise group (AEG) and control group (CG). Pain was assessed by KOOS. Descriptive statistics and Univariate Analyses of Covariance (ANCOVA) were used as primary analyses.

Results: Final sample included 48 adults (BMI: $35.0 \pm 4.9 \mathrm{~kg} / \mathrm{m}^{2}$, age: $55 \pm 7$ years), 23 in the CG and 25 in AEG. Table 1 presents ANCOVA analysis for each item of Pain dimension of KOOS. Significant group effect was found in all pain items $(p<.05)$, except for pain frequency (P1) and pain on bending knee fully (P4). Better group effect was found in the item pain on walking (P5) ( $p<.001)$. Conclusions: PICO aquatic program was effective in improving knee pain in seven of nine activities in individuals with KOA. Key words: Knee pain; aquatic exercise; osteoarthritis; overweight.

Título: Efectividad del ejercicio acuático para cambiar el dolor y los síntomas (dos dimensiones de KOOS)

Antecedentes: El dolor es el síntoma principal de la osteoartritis de rodilla (KOA) y el ejercicio acuático se ha indicado como un tratamiento no farmacológico eficaz para los síntomas de KOA. En general, el dolor por KOA se evalúa mediante escalas simples o mediante cuestionarios autoinformados de múltiples componentes, principalmente el índice de la lesión de rodilla y osteoartritis (KOOS) y el índice de osteoartritis de WOMAC. Algunos estudios informaron la efectividad del ejercicio acuático en la dimensión del dolor de KOOS, pero no en cada ítem del dolor.

Objetivos: Este estudio tuvo como objetivo investigar la efectividad del ejercicio acuático para cambiar el dolor y los síntomas (dos dimensiones de KOOS) durante 3 meses para personas con sobrepeso y obesas con KOA (PICO).

Método: Los criterios de elegibilidad fueron $40 \leq$ edad $\leq 65$ años; IMC $\geq 28 \mathrm{~kg} / \mathrm{m}^{2} ; \mathrm{KOA}$ clínico y radiográfico. Los participantes fueron asignados al azar en el grupo de ejercicio acuático (AEG) y el grupo de control (CG). El dolor fue evaluado por el valor de KOOS. La estadística descriptiva y los análisis univariados de covarianza (ANCOVA) se utilizaron como análisis primarios.

Resultados: La muestra final incluyó 48 adultos (IMC: $35.0 \pm 4.9 \mathrm{~kg} / \mathrm{m}^{2}$, edad: $55 \pm 7$ años), 23 en el CG y 25 en AEG. La Tabla 1 presenta el análisis ANCOVA para cada elemento de la dimensión del dolor de KOOS. Se encontró un efecto de grupo significativo en todos los ítems de dolor $(p<.05)$, excepto la frecuencia del dolor (P1) y el dolor en la flexión de la rodilla por completo (P4). Se encontró un mejor efecto de grupo en el ítem de dolor al caminar (P5) $(p<.001)$.

Conclusiones: El programa acuático PICO fue eficaz para mejorar el dolor de rodilla en siete de nueve actividades en individuos con KOA.

Palabras clave: Dolor de rodilla; ejercicio acuático; osteoartritis; sobrepeso.

Titulo: Dose-resposta dos ítens das dimensões Dor e Sintomas do questionário KOOS ao exercício aquático

Contexto: A dor é o principal sintoma da Osteoartrose do Joelho (KOA) e o exercício aquatico tem sido indicado como um tratamento não-farmacológico eficaz para os seus sintomas. Em geral, a dor da KOA é avaliada através de escalas simples ou por questionários de auto-relato com múltiplas componentes, maioritariamente o Questionário de Índice de Lesão do Joelho e Osteoartrose (KOOS) e o Índice de osteoartrose WOMAC. Alguns estudos reportam a eficácia do exercício aquático na dimensão dad or do KOOS mas não em todos os ítens da dor.

Objetivos: Este estudo pretende investigar como os itens da dor do questionário KOOS são afectadas por um programa de exercício aquático de 3 meses em indivíduos com excesso de peso e obesos com KOA (PICO).

Método: Os critérios de elegibilidade foram $40 \leq$ idade $\leq 65$ anoss; $\mathrm{BMI} \geq 28 \mathrm{~kg} / \mathrm{m}^{2} ; \mathrm{KOA}$ clínica e radiográfica. Os participantes foram aleatorizados em grupo de exercício aquatic (AEG) e grupo de control (CG). Dor e sintomas avaliados pelo KOOS. Estatística descritiva e Univariate Analyses of Covariance (ANCOVA) foram usadas como analises primárias.

Resultados: A amostra final incluiu 48 adultos (BMI: $35.0 \pm 4.9 \mathrm{~kg} / \mathrm{m}^{2}$, idade: $55 \pm 7$ anos), 23 no CG e 25 no AEG. A Tabela 1 apresenta a análise ANCOVA para cada item das diemnsões dor e sintomas do KOOS. Foi encontrado um efeito significativo em todos os itens da dor ( $p<.05)$, except na frequência da dor (P1) e na dor na flexão total do joelho (P4). O melhor efeito foi encontrado no item dad or em marcha (P5) $(p<.001)$

Conclusoes: O programa aquático PICO foi eficaz em melhorar a dor do joelho em sete de nove actividades em indivíduos com KOA Palavras-chave: Dor do joelho; exercício aquático, osteoartrose, excesso de peso 


\section{Introduction}

Pain is the most reported symptom that affects people's life quality in multiple negative forms at individuals with knee osteoarthritis (KOA). Although it is very often underestimated, it causes irritability, sleeplessness, depression and other physical and psychological changes. As a consequence it occurs a disease aggravate, a drop of physical activity level and a loss of physical function (Farr et al., 2008). The present recommendations of the Osteoarthritis Research Society International (OARSI), the American College of Rheumatology (ACR), and the European League Against Rheumatism (EULAR) include exercise as a key point in the KOA management (Hochberg et al., 2012; Jordan et al., 2003; Zhang et al., 2010).

Exercise is a broad concept that encompasses many forms including resistance, isokinetic, and aerobic exercise. All types of exercise could significantly relieve knee osteoarthritis joint pain and improve physical function (Brosseau et al., 2017; Coudeyre et al., 2016). Land and water-based exercise programs are recommended as an important nonpharmacologic option. Both can be designed to increase muscle strength and overall fitness of patients with KOA. Despite land-based exercise is highly recommended for KOAs treatment, when compared with control interventions, there is moderate evidence that aquatic exercise (AE) has small short-term (immediately after treatment) improvement in pain, disability, and quality of life in people with KOA (Franco, Morelhao, de Carvalho, \& Pinto, 2017). Therefore, it is recommended that aquatic exercise with low weight loss and low joint pressure is used in prevention or treatment of osteoarthritis (Batterham, Heywood, \& Keating, 2011; Rahmann, 2010).

$\mathrm{AE}$ is an exercise modality which can be defined as a group of exercises performed in the water, mainly in the vertical position, with or without music, with or without equipment added and in shallow or deep water. It has many advantages compared to land-based exercise. Firstly, the relatively constant water temperature and hydrostatic pressure may facilitate blood circulation, ease soft-tissue contracture, and relieve muscle spasms and fatigue. Secondly, once water resistance acts in the opposite direction of body motion, greater muscle activity is required, which may enhance muscular strengthening. Thirdly, water buoyancy can reduce the likelihood of injury, and protect against joint degradation by reducing weight bearing (Kim, Chung, Park, \& Kang, 2012; Silva et al., 2008; Suomi \& Collier, 2003). Additionally, the element of hot water is believed to reduce pain and stiffness of the musculoskeletal system and cause muscle relaxation (Franco et al., 2017). AE also provides a more comfortable and suitable environment for patients with KOA who are reluctant to exercise (Kim et al., 2012). Therefore, AE may be a beneficial treatment for KOA.

Beside all of these $A E$ benefits, the biggest challenge is providing an activity regime that is both acceptable within its intended target population and also decreases pain on the affected joints. From this perspective, novel approaches to exercise are necessary (Seib \& Anderson, 2017). Statistical analysis indicated that arthritic patients present a lower level of physical activity compared to the general population (Rosemann, Kuehlein, Laux, \& Szecsenyi, 2008) and nearly $50 \%$ of OA individuals were reluctant to do extra exercise due to pain (Bartels et al., 2007; Gay, Chabaud, Guilley, \& Coudeyre, 2016).Even if they participated in a physical exercise program, long-term adherence is problematic. Therefore, once again, it is important to explore other treatment options for patients with knee OA (Dong et al., 2018).

KOOS is the most used questionnaire to evaluate KOA symptoms and its effects on patients quality of life. At the majority of the interventions we searched about where KOOS was used as a tool, the authors just paid their attention to final outcomes. It is a fact that KOOS general outcome gives us a big picture of how intense is the pain and how it is reflected on patients life's quality. However, a closer look to each questionnaire dimensions, individualizing each score and its variation when exposed to exercise, will be even more valuable for professionals to make their choices when prescribing exercise and giving physical activities advise.

This study aimed to investigate how symptoms items of KOOS questionnaire are affected by a 3 months aquatic exercise program for KOA individuals through PICO Project (an aquatic exercise program against KOA). Thus, the results from PICO project were used to provide a better understanding about these items behavior in response to aquatic exercise. Detailed information about the PICO methodology can be found in the protocol study, previously published (Yazigi et al., 2013b).

\section{Method}

\section{Subjects}

Initially 52 individuals were randomized into two groups, three were excluded from the CG and only one participant was excluded from AEG due to health reasons. The final sample included 48 participants who completed the program and performed all tests. The majority of participants were within the age interval of 50-59 years. Across all participants, the mean age was $55 \pm 7$ years, the mean weight was $90.8 \pm 13.9 \mathrm{~kg}$, the mean height was $161 \pm 10 \mathrm{~cm}$ and $\mathrm{BMI}$ was $35.0 \pm 4.9$ $\mathrm{kg} / \mathrm{m}^{2}$.

\section{Instruments}

Knee Injury and Osteoarthritis Outcome Score (KOOS). This questionnaire included five dimensions to measure KOA-specific health-related quality of life (QOL), knee pain (Pain), other diseasespecific symptoms (O.Symptoms), activities of daily living (ADL), and sport/recreation function (Sport/Rec). A score in each dimension was calculated as the sum of the items included and was then converted to a 0-100 scale, with 0 representing extreme knee problems and 100 representing no knee problems. KOOS is validated for patients with knee injury or with KOA and it is a reliable and responsive selfadministered instrument for short-term follow-up (Roos \& Lohmander, 2003). The Portuguese validation has acceptable reliability with Cronbach's alpha coefficients between 0.77 and 0.95 and ICC ranging from 0.82 to 0.94 for the KOOS subscales (Goncalves, Cabri, Pinheiro, \& Ferreira, 2009).

\section{Procedures}

PICO is a single-blinded, randomized controlled trial with 3 months duration (Yazigi et al., 2013b). Participants were randomly assigned to one of two groups: aquatic exercise (AEG) and control groups (CG). The study protocol was approved by the Ethical Committee of the Faculty of Human Kinetics, Technical University of Lisbon. All participants were informed about the procedures and potential risks and an informed consent was obtained from them.

The aquatic program was based on OARSI and EULAR Guidelines for KOA management (Jordan et al., 2003; Zhang et al., 2010), on the Aquatic Exercise Association Guidelines (AEA), on the Arthritis Foundation Aquatics Program instructor's manual, on the ACSM's Guidelines for Exercise Prescription and on the analysis of protocols from previous studies (Bartels et al., 2016; Batterham et al., 2011; Lim, Tchai, \& Jang, 2010; Messier et al., 2009; Pais, 2007; Wang et al., 2011). The aquatic program was organized into 24 sessions, which were distributed over 12 consecutive weeks, with a frequency of twice a week. Each session lasted for 60 minutes and the first 10 minutes were saved for patient's reception, blood pressure control, pain registry and educational talks. The effective time inside water was 45 minutes. All sessions had a controlled intervention regarding music type, warm-up, 
exercises patterns, intensity and pain management and motivational strategies. Details are available in the PICO protocol (Yazigi et al., 2013a). The indoor pool area had an air temperature of approximately $27 \pm 1 \stackrel{\circ}{ } \mathrm{C}$ and a controlled water temperature of $30.5 \pm 0.5 \circ \mathrm{C}$.

\section{Statistical Analysis}

Descriptive statistics, including frequencies for categorical variables, means with standard deviations (SD) for continuous variables was used. Normal distributions of continuous variables were tested by Kolmogorov-Smirnov test. Correlation between continuous variables at baseline was analyzed using Pearson correlation coefficient $(r)$ interpreted as strong $(r \geq 0.7)$, moderate $(0.5<r<0.7)$ and weak $(0.3<r<0.5)$, and the coefficient of determination was used to interpret $r$ and was obtained by squaring the correlation coefficient $r\left(r^{2}\right)$ (Taylor, 1990). The differences in mean change (baseline minus post-intervention) were compared between groups using the analysis of covariance, adjusted for baseline values of the outcome. Comparisons of changes between groups (CG and AEG) were performed as primary analysis by Univariate analyses of covariance (ANCOVA) where dependent variables were adjusted for baseline pain, gender, BMI, and baseline values. Statistical analysis was performed using IBM SPSS Statistics 20.0 and MedCalc Statistical Software (MedCalc Software, Mariakerke, Belgium). Statistical significance was set at $p<.05$ (2-tailed) for all analyses.

\section{Results}

The mean changes between groups in both dimensions of KOOS were significant different $(p<.001)$ : KOOS pain changed in the CG from $50.2 \pm 20$ to $53.7 \pm 19$ and from $45.3 \pm 12$ to $69.6 \pm 19$ in the AE group. KOOS O.Symptoms changed in the CG from $55.2 \pm 23$ to $55.9 \pm 20$ and from $46.6 \pm 18$ to $66.7 \pm 19$ in the AEG.

Table 1 presents ANCOVA analysis for each item of the O. Symptoms and Pain dimensions of KOOS. No group effect was observed in the questions S5-S7 and in the pain frequency (P1) and pain on bending (P4). Significant group effect were found on four items of symptoms, swelling (S1), knee noise (S2), knee hang up (S3) and straighten (S4). Regarding pain items, higher group effect was found for pain on walking (P5) and on up and downstairs activity (P6).

Table1. Group effect analysis for questions scores of Symptoms (S1-S7) and Pain (P1-P9) dimensions of KOOS questionnaire (0-4 where 4 is the worst condition). ANCOVA adjusted for sex BMI value no baseline.

\begin{tabular}{|c|c|c|c|c|c|c|c|c|}
\hline & \multicolumn{3}{|c|}{ Control Group } & \multicolumn{3}{|c|}{ Aquatic Exercise Group } & \multirow{2}{*}{\multicolumn{2}{|c|}{$\begin{array}{c}\text { ANCOVA } \\
\text { Group effect }\end{array}$}} \\
\hline & \multirow{2}{*}{$\begin{array}{c}\text { Mom1 } \\
\operatorname{Mean}(S D)\end{array}$} & \multirow{2}{*}{$\begin{array}{c}\operatorname{Mom} 2 \\
\operatorname{Mean}(S D)\end{array}$} & \multirow{2}{*}{$\begin{array}{l}\text { Changes }^{8} \\
\text { Mean(SD) }\end{array}$} & \multirow{2}{*}{$\begin{array}{c}\operatorname{Mom1} 1 \\
\operatorname{Mean}(S D)\end{array}$} & \multirow{2}{*}{$\begin{array}{c}\text { Mom2 } \\
\operatorname{Mean}(S D)\end{array}$} & \multirow{2}{*}{$\begin{array}{l}\text { Changes }^{8} \\
\text { Mean }(S D)\end{array}$} & & \\
\hline & & & & & & & $\mathrm{F}$ & $p$-value \\
\hline S1:Sweelling & $1.6(1.4)$ & $1.7(1.2)$ & $-0.1(0.8)$ & $2.0(1.4)$ & $1.3(1.1)$ & $0.7(1.3)$ & 4.75 & $.035^{*}$ \\
\hline S2:Noise & $2.0(1.1)$ & $2.0(1.1)$ & $0.0(0.5)$ & $2.7(1.1)$ & $1.9(1.0)$ & $0.8(0.9)$ & 7.01 & $.011^{*}$ \\
\hline S3:Knee Hang up & $2.1(1.2)$ & $1.9(0.9)$ & $0.3(1.0)$ & $2.3(0.8)$ & $1.4(0.9)$ & $0.9(0.9)$ & 7.49 & $.009 * *$ \\
\hline S4:Straighten & $0.9(1.0)$ & $1.2(1.1)$ & $-0.3(1.2)$ & $1.4(1.2)$ & $0.8(1.2)$ & $0.6(1.0)$ & 6.23 & $.016 * *$ \\
\hline S5:Bend & $1.5(1.3)$ & $1.6(13)$ & $-0.1(1.0)$ & $1.8(1.3)$ & $1.4(1.6)$ & $0.4(1.4)$ & 2.16 & 149 \\
\hline S6:Morning Stiffness & $2.0(1.1)$ & $1.7(1.1)$ & $0.3(1.2)$ & $2.3(1.0)$ & $1.3(0.9)$ & $1.0(1.2)$ & 3.52 & .068 \\
\hline 57:Position Stiffness & $2.2(1.2)$ & $2.0(1.2)$ & $0.2(0.9)$ & $2.4(0.8)$ & $1.6(1.1)$ & $0.8(1.1)$ & 3.37 & . 073 \\
\hline P1:Frequency & $2.9(0.9)$ & $2.7(0.9)$ & $0.2(0.9)$ & $3.0(0.7)$ & $2.3(1.0)$ & $0.7(1.3)$ & 2.87 & . 097 \\
\hline P2:Twisting & $1.9(0.9)$ & $1.9(1.0)$ & $0.0(1.1)$ & $2.4(0.6)$ & $1.4(1.0)$ & $1.0(1.0)$ & 6.41 & $.015^{* *}$ \\
\hline P3: Straighten & $1.6(0.9)$ & $1.7(1.0)$ & $-0.1(1.4)$ & $1.9(0.9)$ & $1.0(1.1)$ & $0.9(1.1)$ & 6.88 & $.012^{* *}$ \\
\hline P4:Bending & $2.0(1.3)$ & $1.8(1.2)$ & $0.2(0.8)$ & $2.3(0.8)$ & $1.5(1.2)$ & $0.8(1.4)$ & 1.97 & 168 \\
\hline P5:Walking & $1.1(0.8)$ & $1.5(0.9)$ & $-0.4(1.0)$ & $1.6(0.8)$ & $0.6(0.8)$ & $1.0(0.9)$ & 19.07 & $<.001^{* * *}$ \\
\hline P6:Up/Down & $2.3(1.3)$ & $2.2(1.2)$ & $0.1(0.9)$ & $2.8(0.6)$ & $1.5(1.1)$ & $1.3(1.1)$ & 12.49 & $.001 * *$ \\
\hline P7:At night & $1.4(1.0)$ & $1.5(1.1)$ & $-0.1(1.1)$ & $1.8(0.9)$ & $0.8(0.9)$ & $1.0(1.2)$ & 9.72 & $.003^{* *}$ \\
\hline P8:Sitting & $1.3(0.9)$ & $1.3(1.0)$ & $0.0(0.9)$ & $1.6(0.8)$ & $0.8(0.9)$ & $0.8(1.0)$ & 7.06 & $.011^{*}$ \\
\hline P9:Standing up & $1.8(1.0)$ & $1.6(1.1)$ & $0.2(0.7)$ & $2.2(0.8)$ & $1.2(1.2)$ & $1.0(1.2)$ & 5.54 & $.023^{*}$ \\
\hline
\end{tabular}

Some items of CG registered worsening condition, while the $A E G$ had improvements in all items: $S 1$ (CG=-6\%; $A E G=35 \%) ; S 2$ (CG=0\%; $\mathrm{AEG}=30 \%$ ); $\mathrm{S3}$ ( $\mathrm{CG}=14 \% ; \mathrm{AEG}=39 \%$ ); $\mathrm{S} 4$ (CG=-33\%; $\mathrm{AEG}=43 \%$ ); $\mathrm{S} 5$ (CG=$7 \% ; \mathrm{AEG}=22 \%) ; \mathrm{S} 6$ (CG=15\%; $\mathrm{AEG}=43 \%) ; \mathrm{S7}$ (CG=9\%; $\mathrm{AEG=39 \% );P1}$ (CG=7\%; $A E G=23 \%) ; P 2(C G=0 \% ; A E G=42 \%) ; P 3$ (CG=-6\%; $A E G=47 \%) ; P 4$ (CG=10\%; $A E G=35 \%) ; P 5$ (CG=-36\%; AEG=63\%); P6 (CG=4\%; $A E G=46 \%) ;$
P7 (CG=-7\%; $A E G=56 \%) ; P 8$ (CG=0\%; $A E G=50 \%)$ and P9 (CG=11\%; $\mathrm{AEG}=45 \%$ ).

\section{Discussion}

The positive changes on KOA symptoms found in the present study reflect the multicomponent approach of PICO aquatic exercise program and corroborate the findings of Hinman and coworkers (Hinman, Heywood, \& Day, 2007) and Kim and coworkers (Kim et al., 2012). In general, changes in KOOS in the AEG were above $40 \%$ and quite superior to the changes of symptoms reported in other studies (Kim et al., 2012; Lund et al., 2008; Suomi \& Collier, 2003; Thorstensson, Roos, Petersson, \& Ekdahl, 2005; Wang et al., 2011). Although Lund (Lund et al., 2008) did not observe changes after $16 \mathrm{AE}$ sessions, improvements of $13 \%$ after 36 sessions were reported by Wang (Wang et al., 2011). The detailed analysis of the group effect for each item of KOOS symptoms and KOOS pain (Table 1) provided interesting information about the dose-response to exercise and how it affected the total score of KOOS dimensions. Three items of symptoms showed no group effect (S5, S6 and S7). Concerning the ability to bend the knee (S5), the absence of changes could be due to the fact that our sample population was obese, and their anthropometric measures, weight and fear of falling could have been a constraint to bending the knee. Our expectation is that this should change with long-term interventions and subsequent weight loss. In contrast to the aquatic program of Hinnan and coworkers (Hinman et al., 2007), our results for both stiffness items (S6 and S7) did not show significant changes. Those authors attributed their reduction of joint stiffness to the warm water $\left(34{ }^{\circ} \mathrm{C}\right)$, which was higher than the temperature used in our PICO aquatic program $(30.5 \circ \mathrm{C})$. With respect to the other symptoms, significant group effects were found for swelling (S1), noise (S2), knee hang up (S3) and knee straightening ( $\mathrm{S} 4)$. The change in these symptoms could be attributed to a decrease in pain, better joint lubrication and improvement in functional strength. Swellings reduction may be attributed to the fact that the exercise protocol had been performed in water; if the exercise was performed on land, the joint overload of weight bearing exercises could have caused a contrary effect. Moreover, as described by the principles of hydrodynamics, hydrostatic pressure makes aquatic exercise very different from land-based exercise (which is important to consider clinically). Hydrostatic pressure increases $1 \mathrm{mmHg}$ every 1.36 $\mathrm{cm}$ of water depth. This means that at $1.2 \mathrm{~m}$ of body immersion the pressure around the limb is higher than normal diastolic pressure and could aid venous return (Becker, 2009). This supports the clinical observation that edema or swelling are reduced after immersion (Hartmann \& Huch, 2005; Rahmann, 2010). Most likely, joints with reduced swelling can accomplish a larger range of motion, thereby improving movements.

Our results demonstrate that the stronger cardiorespiratory component associated with the specific water properties, namely buoyancy and hydrostatic pressure, contributed to the great improvements in KOA symptoms, including a knee noise, swelling and pain reduction. Water buoyancy can diminish lower extremities joint loading and, thereby, reduce gravity effects.

\section{Conclusion}

The PICO Project highlighted the importance of developing a controlled and detailed aquatic exercise protocol that, beyond pathology expertise, requires a deep knowledge about the fundamentals of aquatic exercise with aquatic instructors having advanced teaching skills.

It can be concluded that aquatic exercise has a positive effect on both dimensions of KOOS (Pain and Symptoms). Being that, stiffness and other morphological items did not have a significant response. In spite of that, items related with functional patterns did have a positive 
responsiveness to exercise and are the ones which contribute the most to the positive final score. This may lead us to conclude that aquatic exercise, although it does not improve muscular aspects, improve life's quality by diminishing pain sensation.

For future approaches, professionals working with aquatic exercise programs for KOA patients should notice that, if they know how to work with water properties and enhance the positive effect that exercise will have on their daily living activities, they will be exponentially increasing their success rates.

\section{Contribution and practical implications}

The PICO aquatic project provided relevant insights into the exercise intervention field. It showed that aquatic exercise, when well designed using a controlled methodology, is effective at improving all fitness components in adults, not just the elderly. Furthermore, the present study showed that aquatic exercise is a suitable option for obese individuals to control KOA symptoms and initiate a weight loss process. In this way an important message for all weight control programs and for exercise's professionals is that KOA symptoms, mainly pain, must be identified and controlled, otherwise it becomes a constraint for meeting exercise goals.

\section{Acknowledgment}

Without institutional support, the PICO project would not be possible. In this way, I would like to thank to the Portuguese Institute of Rheumatology, to the Instituto Português do Desporto e Juventude, which provided the swimming pool, for the classes realization and also, to the laboratories of Faculdade de Motricidade Humana (Biomechanics and Functional Morphology lab, Health and Exercise lab and Biochemistry and Exercise Physiology lab), which supported the tests realization. Additionally, my thanks for Fundação da Ciência e Tecnologia, for my scholarship (SFRH/BD/46425/2008).

\section{References}

Bartels, E. M., Juhl, C. B., Christensen, R., Hagen, K. B., Danneskiold-Samsoe, B., Dagfinrud, H., \& Lund, H. (2016). Aquatic exercise for the treatment of knee and hip osteoarthritis. Cochrane Database Systematic Reviews, 3, CD005523. doi:10.1002/14651858.CD005523.pub3

Bartels, E. M., Lund, H., Hagen, K. B., Dagfinrud, H., Christensen, R., \& Danneskiold-Samsoe, B. (2007). Aquatic exercise for the treatment of knee and hip osteoarthritis. Cochrane Database Systematic Reviews, 17(4), CD005523. doi:10.1002/14651858.CD005523.pub2

Batterham, S. I., Heywood, S., \& Keating, J. L. (2011). Systematic review and meta-analysis comparing land and aquatic exercise for people with hip or knee arthritis on function, mobility and other health outcomes. BMC Musculoskelet Disord, 12, 123. doi:10.1186/1471-2474-12-123

Becker, B. E. (2009). Aquatic therapy: scientific foundations and clinical rehabilitation applications. Physical Medicine and Rehabilitation, 1(9), 859-872. doi:10.1016/j.pmrj.2009.05.017

Brosseau, L., Taki, J., Desjardins, B., Thevenot, O., Fransen, M., Wells, G. A.,... McLean, L. (2017). The Ottawa panel clinical practice guidelines for the management of knee osteoarthritis. Part two: strengthening exercise programs. Clinical Rehabilitation, 31(5), 596-611. doi:10.1177/0269215517691084

Coudeyre, E., Jegu, A. G., Giustanini, M., Marrel, J. P., Edouard, P., \& Pereira, B. (2016). Isokinetic muscle strengthening for knee osteoarthritis: A systematic review of randomized controlled trials with meta-analysis. Annals of Physical and Rehabilitation Medicine, 59(3), 207-215. doi:10.1016/j.rehab.2016.01.013

Dong, R., Wu, Y., Xu, S., Zhang, L., Ying, J., Jin, H., . . Tong, P. (2018). Is aquatic exercise more effective than land-based exercise for knee osteoarthritis? Medicine (Baltimore), 97(52), e13823. doi:10.1097/MD.0000000000013823

Farr, J. N., Going, S. B., Lohman, T. G., Rankin, L., Kasle, S., Cornett, M., \& Cussler, E. (2008). Physical activity levels in patients with early knee osteoarthritis measured by accelerometry. Arthritis \& Rheumatology, 59(9), 1229-1236. doi:10.1002/art.24007

Franco, M. R., Morelhao, P. K., de Carvalho, A., \& Pinto, R. Z. (2017). Aquatic Exercise for the Treatment of Hip and Knee Osteoarthritis. Physical Therapy, 97(7), 693-697. doi:10.1093/ptj/pzx043

Gay, C., Chabaud, A., Guilley, E., \& Coudeyre, E. (2016). Educating patients about the benefits of physical activity and exercise for their hip and knee osteoarthritis. Systematic literature review. Annals of Physical and Rehabilitation Medicine, 59(3), 174-183. doi:10.1016/j.rehab.2016.02.005

Goncalves, R. S., Cabri, J., Pinheiro, J. P., \& Ferreira, P. L. (2009). Crosscultural adaptation and validation of the Portuguese version of the Knee injury and Osteoarthritis Outcome Score (KOOS). Osteoarthritis Cartilage, 17(9), 1156-1162. doi:10.1016/j.joca.2009.01.009

Hartmann, S., \& Huch, R. (2005). Response of pregnancy leg edema to a single immersion exercise session. Acta Obstetricia et Gynecologica Scandinavica, 84(12), 1150-1153. doi:10.1111/j.00016349.2005.00829.x

Hinman, R. S., Heywood, S. E., \& Day, A. R. (2007). Aquatic physical therapy for hip and knee osteoarthritis: results of a single-blind randomized controlled trial. Physical Therapy, 87(1), 32-43. doi:10.2522/ptj.20060006

Hochberg, M. C., Altman, R. D., April, K. T., Benkhalti, M., Guyatt, G., McGowan, J., ... Tugwell, P. (2012). American College of Rheumatology 2012 recommendations for the use of nonpharmacologic and pharmacologic therapies in osteoarthritis of the hand, hip, and knee. Arthritis Care \& Research, 64(4), 465-474.

Jordan, K. M., Arden, N. K., Doherty, M., Bannwarth, B., Bijlsma, J. W., Dieppe, P., ... Dougados, M. (2003). EULAR Recommendations 2003: an evidence based approach to the management of knee osteoarthritis: Report of a Task Force of the Standing Committee for International Clinical Studies Including Therapeutic Trials (ESCISIT). Annals of The Rheumatic Diseases, 62(12), 1145-1155.

Kim, I. S., Chung, S. H., Park, Y. J., \& Kang, H. Y. (2012). The effectiveness of an aquarobic exercise program for patients with osteoarthritis. Applied Nursing Research, 25(3), 181-189. doi:10.1016/j.apnr.2010.10.001

Lim, J. Y., Tchai, E., \& Jang, S. N. (2010). Effectiveness of aquatic exercise for obese patients with knee osteoarthritis: a randomized controlled trial. Physical Medicine and Rehabilitation, 2(8), 723-731; quiz 793. doi:10.1016/j.pmrj.2010.04.004

Lund, H., Weile, U., Christensen, R., Rostock, B., Downey, A., Bartels, E. M., ... Bliddal, H. (2008). A randomized controlled trial of aquatic and landbased exercise in patients with knee osteoarthritis. Journal of Rehabilitation Medicine, 40(2), 137-144. doi:10.2340/16501977-0134

Messier, S. P., Legault, C., Mihalko, S., Miller, G. D., Loeser, R. F., DeVita, P., ... Nicklas, B. J. (2009). The Intensive Diet and Exercise for Arthritis (IDEA) trial: design and rationale. BMC Musculoskelet Disord, 10, 93. doi:10.1186/1471-2474-10-93

Pais, S. C. (2007). Aquatic exercise in knee osteoarthritis Patients: effects on symptoms, range of motion, proprioception, strength,function, ground reaction forces and plantar pressures. (PhD. PhD), Univ de Lisboa, Lisboa. Retrieved from http://bibliotecas.utl.pt/cgi-bin/koha/opacISBDdetail.pl?biblionumber=368280 (TD043 FMH MH8 2007 )

Rahmann, A. E. (2010). Exercise for people with hip or knee osteoarthritis: a comparison of land-based and aquatic interventions. Open Access Journal of Sports Medicine, 1, 123-135.

Roos, E. M., \& Lohmander, L. S. (2003). The Knee injury and Osteoarthritis Outcome Score (KOOS): from joint injury to osteoarthritis. Health and Quality of Life Outcomes, 1, 64. doi:10.1186/1477-7525-1-64

Rosemann, T., Kuehlein, T., Laux, G., \& Szecsenyi, J. (2008). Factors associated with physical activity of patients with osteoarthritis of the lower limb. Journal of Evaluation in Clinical Practice, 14(2), 288-293. doi:10.1111/j.1365-2753.2007.00852.x

Seib, C., \& Anderson, D. (2017). Can dance-based aquatic exercise improve functionality in obese women with knee osteoarthritis? Menopause, 24(7), 724-725. doi:10.1097/GME.0000000000000930

Silva, L. E., Valim, V., Pessanha, A. P., Oliveira, L. M., Myamoto, S., Jones, A., \& Natour, J. (2008). Hydrotherapy versus conventional land-based exercise for the management of patients with osteoarthritis of the knee: a randomized clinical trial. Physical Therapy, 88(1), 12-21. doi:10.2522/ptj.20060040 
Suomi, R., \& Collier, D. (2003). Effects of arthritis exercise programs on functional fitness and perceived activities of daily living measures in older adults with arthritis. Archives of Physical Medicine and Rehabilitation, 84(11), 1589-1594.

Taylor, R. (1990). Interpretation of the correlation coefficient: a basic review. Journal of Diagnostic Medical Sonography, 6(January), 35-39. doi:10.1177/875647939000600106

Thorstensson, C. A., Roos, E. M., Petersson, I. F., \& Ekdahl, C. (2005). Sixweek high-intensity exercise program for middle-aged patients with knee osteoarthritis: a randomized controlled trial [ISRCTN20244858]. BMC Musculoskelet Disord, 6, 27. doi:10.1186/1471-2474-6-27

Wang, T. J., Lee, S. C., Liang, S. Y., Tung, H. H., Wu, S. F., \& Lin, Y. P. (2011). Comparing the efficacy of aquatic exercises and land-based exercises for patients with knee osteoarthritis. Journal of Clinical Nursing, 20(1718), 2609-2622. doi:10.1111/j.1365-2702.2010.03675.x

Yazigi, F., Pinto, S., Colado, J., Escalante, Y., Armada-Da-Silva, P., Brasil, R., \& Alves, F. (2013a). The cadence and water temperature effect on physiological responses during water cycling. European Journal of Sport Science, 1-7. doi:10.1080/17461391.2013.770924

Yazigi, F., Pinto, S., Colado, J., Escalante, Y., Armada-Da-Silva, P. A., Brasil, R. \& Alves, F. (2013b). The cadence and water temperature effect on physiological responses during water cycling. European Journal of Sport Science. doi:10.1080/17461391.2013.770924

Zhang, W., Nuki, G., Moskowitz, R. W., Abramson, S., Altman, R. D., Arden, N. K.,... Tugwell, P. (2010). OARSI recommendations for the management of hip and knee osteoarthritis: part III: Changes in evidence following systematic cumulative update of research published through January 2009. Osteoarthritis Cartilage, 18(4), 476-499. doi:10.1016/j.joca.2010.01.013 